\title{
O MARXISMO LIBERTÁRIO DE MICHAEL LÖWY
}

\author{
Enzo Traverso*
}

\begin{abstract}
Neste ensaio, originalmente proferido como conferência, Enzo Traverso analisa algumas das linhas de força da trajetória intelectual de Michael Löwy, dos seus primeiros trabalhos sobre Marx, Lukács e Goldmann às suas reflexões mais recentes sobre Benjamin ou sobre o romantismo. Aplicando à análise do autor o mesmo método que ele utilizara para compreender os autores sobre os quais investigou, Traverso defende a hipótese de que, embora nascido no Brasil, Löwy pode ser visto como um "intelectual francês que combina e supera duas tradições que marcaram profundamente a história, a cultura e a política do século XX: a do judaísmo da Europa Central de antes da Schoah e a da esquerda latino-americana posterior à revolução cubana".

Palavras-chave: Intelectuais. Judaísmo. Europa Central. América Latina. Marxismo libertário.
\end{abstract}

O objetivo deste breve ensaio não é o de analisar algum aspecto específico da vasta e multiforme obra de Michael Löwy, mas sim o de tentar apreender sua trajetória em seu conjunto. Sua primeira obra, dedicada ao jovem Marx, se apresenta como "uma análise marxista da gênese do próprio marxismo" (Löwy, 1970b, p. 11). Essa questão, que remete a Georg Lukács e Lucien Goldmann, é retomada em diversos dos seus escritos, nos quais se coloca "a espinhosa questão da aplicação do materialismo histórico sobre si mesmo” (Löwy, 1985, p.101). ${ }^{2}$ O problema é complexo e mereceria um tratamento à parte; concentrar-me-ei, aqui, no método. A ideia é retraçar o itinerário intelectual de Michael Löwy à luz de sua própria sociologia histórica, adotando um método que ele me ensinou há mais de um quarto de século, quando foi orientador da minha tese na École des Hauts Études em Sciences Sociales

* Universidade de Cornell. College of Arts\&Sciences. Klarman Hall, Room K261. Cornell University - USA. vt225@cornell.edu

${ }^{1}$ Traduzido do francês por Fabio Mascaro Querido.

${ }^{2}$ Cf. também Goldmann (1963, p.114-118).
(EHESS), em Paris, na França.

Há várias maneiras de "cercar" a obra de Michael Löwy. Em um belo ensaio, o sociólogo da UNICAMP Ricardo Antunes (2007, p. 20) o define como um intelectual brasileiro que articula um rigor teórico europeu bastante sofisticado e um forte espírito latino-americano. Sem tê-lo conhecido no Brasil, proponho uma definição um pouco diferente. A meus olhos, Michael Löwy é um intelectual francês que combina e supera duas tradições que marcaram profundamente a história, a cultura e a política do século XX: a do judaísmo da Europa Central de antes da $S c h o a h^{3}$ e a da esquerda latino-americana posterior à revolução cubana. A França foi o lugar de encontro e de síntese - de uma Aufhebung dialética, pode-se dizer, com uma fórmula hegelo-marxista que ele muito apreciava - entre essas tradições, que, em vez de se justaporem, são amalgamadas e interpenetradas até se criar algo novo e singular. Seria possível falar de alquimia ou,

${ }^{3}$ Originário de um dialeto alemão falado pelos judeus ocidentais, e sinônimo de calamidade, Schoah tornou-se o termo em hebraico utilizado para designar o Holocausto, genocídio dos judeus pela Alemanha nazista (nota do tradutor). 
por que não, de "afinidade eletiva”, no sentido em que Löwy teorizou sobre tal conceito: o encontro entre estilos de pensamento diferentes que, ao se articularem, dão vazão a uma "figura nova” (Löwy, 1988, p. 20). Esse encontro, para ocorrer, exige algumas premissas que o tornam possível, mas que não respondem a necessidade objetiva alguma, decorrendo, antes, de uma elaboração criativa que se opera num contexto histórico determinado, concernente a um grupo ou, no caso, a um só indivíduo. Obviamente, a trajetória de Michael Löwy se inscreve naquela de uma geração e de movimentos intelectuais e políticos aos quais ele pertenceu, mas ela guarda algo de irredutivelmente singular.

O Brasil é, sem dúvida, a matriz. Lembro-me de uma carta postal que Löwy me enviou há alguns anos, na qual se via apenas a entrada de um edifício austero e bastante feio. Tratava-se, escreveu ele, da biblioteca que ele tinha frequentado na adolescência e no início da juventude, e suas palavras deixavam transparecer uma afeição verdadeira por esse lugar. No Brasil, antes mesmo de aprender português, Michael Löwy aprendeu o alemão, sua língua materna, no seio de uma família de judeus vienenses exilados. Foi no Brasil que ele descobriu o surrealismo, a psicanálise, Marx, $\infty$ Rosa Luxemburgo e Kafka. Foi no Brasil que ele começou a estudar sociologia, frequentan$\stackrel{8}{8}$ do os cursos de Fernando H. Cardoso, o futuro presidente. E foi também no Brasil que Löwy participou, por volta do final dos anos 1950, da fundação da Liga Socialista Independente. Tudo vai se ancorar nesse tronco, mas sei. ria na França que se operaria a simbiose entre essas correntes, tradições e experiências que, i no Brasil, não passavam de sensibilidades, de

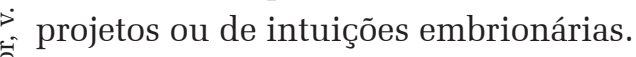
lembrança de sua juventude, mas sim uma região com a qual ele jamais cortou os laços, que ele frequenta regularmente e onde a influência do seu pensamento é considerável. No plano intelectual, sua relação com a cultura política latino-americana passou por três momentos fundamentais. O primeiro foi o impacto do guevarismo, cuja herança ainda é por ele reivindicada como uma "chama que ainda arde" (Löwy; Besancenot, 2007), e que ele interpreta como uma corrente "voluntarista", tanto no plano ético quanto no plano político, em oposição a todo determinismo fatalista e passivo (Löwy, 1980, p. 56). Em seguida, a descoberta da obra de José Carlos Mariátegui, graças ao qual o marxismo deixou de ser um produto de importação a fim de se enraizar na cultura da região, tornando-se expressão autêntica dela. Por fim, a teologia da libertação, responsável pela síntese entre o socialismo e a ética anticapitalista que anima as comunidades de base da Igreja Católica. Dessas três perspectivas, Michael Löwy foi, a um só tempo, o sociólogo, o historiador, o analista crítico e, por certo, bem mais do que um "espectador engajado": ele sempre foi um sábio conselheiro e, em certos casos, um militante ativo.

A outra grande matriz é a cultura da Mitteleuropa, a Europa Central de língua alemã. Aqui também me parece possível distinguir três grandes correntes de pensamento que contribuíram para a formação de Michael Löwy: em primeiro lugar, a sociologia histórica de Weber e Mannheim; depois, o marxismo ocidental, com um deslocamento gradativo de Lukács em direção à Escola de Frankfurt; enfim, o messianismo judaico nas suas múltiplas dimensões, de Scholem a Benjamin, de Buber a Rosenzweig, de Bloch a Kafka. A obra de Löwy foi pensada, em ampla medida, como uma confrontação crítica com essas três correntes de pensamento, com uma atenção particular em relação a certas figuras "transversais", como Lukács, ponto de partida do marxismo-weberiano, e, sobretudo, Benjamin, que elabora uma nova visão da história fundada na síntese entre o marxismo e o messianismo judaico.

O lugar em que essas duas tradições - a latino-americana e a judeu-alemã - se encontraram e se fundiram para criar uma obra nova 
e original é, sem dúvida, a França. Michael Löwy desembarca em Paris para preparar sua tese de doutorado na Sorbonne em 1961, época na qual, para retomar as palavras de Judt (2007, p. 256), "uma vez mais, e pela última vez, Paris foi a capital da Europa”. Era também o principal abrigo dos exilados latino-americanos - moravam em Paris, na época, García Márquez, Vargas Llosa e Cortázar - e o próprio Löwy se tornaria um deles quando, em 1964, um golpe de Estado instaurou uma ditadura militar no Brasil. Mas é graças à mediação de dois dentre os últimos representantes de outro exílio, o exílio judeu-alemão dos sobreviventes da Schoah, que ele descobre a sociologia e o marxismo da Europa Central: o filósofo Lucien Goldmann, que orienta a sua tese sobre o jovem Marx, e o historiador do movimento operário Georges Haupt, dois judeus romenos de língua alemã. Goldmann, em particular, impulsiona Löwy na direção de uma leitura historicista, humanista e radicalmente antipositivista do pensamento de Marx (Löwy; Naïr, 1973). Ele o faz descobrir Lukács e a visão de mundo trágica, ou seja, o ponto de partida de um projeto intelectual cujo desenlace será uma nova concepção do romantismo.

Na Paris do início dos anos 1960, anos da guerra da Argélia e da incubação de maio de 68, Löwy é discípulo de Goldmann. Ele frequenta os cursos de Raymond Aron e Georges Gurvitch, mas permanece impermeável ao estruturalismo, a corrente intelectual então dominante. Alguns anos depois, ele consagra um ensaio bastante crítico a Lire le Capital, obra organizada por Louis Althusser, o grande guru da época (Löwy, 1974, p. 209-228). Para além do estruturalismo, Löwy permaneceu impermeável - o que foi provavelmente uma das condições de elaboração de sua obra - a toda uma tradição sociológica francesa que vai de Durkheim a Bourdieu. Em uma obra metodológica como Paysages de la vérité, Comte e Durkheim são analisados num subcapítulo intitulado "A ideologia positivista" (Löwy, 1985, p. 22-33). Em outras palavras, Löwy elaborou, na França, uma sociologia da cultura estrangeira às correntes dominantes da sociologia francesa. Isso faz dele, de certo modo, um outsider. Seu apego ao marxismo, ao longo dos anos seguintes, em especial a partir da década de 1980, marcados pelo avanço do liberalismo tanto no espaço público quanto no mundo universitário, acentuou ainda mais sua singularidade, sua posição inclassificável. Bem francês, por outro lado, a despeito de sua projeção internacional, é o surrealismo, corrente estética e política à qual Löwy aderiu apaixonadamente, mas numa época em que o movimento havia quase desaparecido, motivo pelo qual sua adesão, tardia e um tanto anacrônica, destaca uma vez mais seu lugar inclassificável e singular na paisagem intelectual.

Formularei uma hipótese. A revolução cubana e a vaga de radicalização política que ela engendrou na América Latina forjaram, em Michael Löwy, uma sensibilidade, um estilo de pensamento, uma forma mentis que constitui o pano de fundo de sua interpretação da sociologia alemã, do marxismo ocidental e do messianismo judaico. Esse background cultural, político e, sem dúvida, igualmente existencial, é a base de um otimismo antropológico que constitui, de certa maneira, um contrapeso à "jaula de aço" weberiana, à dialética negativa do marxismo ocidental, ao Anjo da História de Benjamin; não para recusá-los, mas, sim, para redefini-los. Em vários dos seus escritos, esse otimismo antropológico, ancorado na experiência histórica da América Latina, apresenta-se sob a alcunha "humanismo revolucionário". ${ }^{4}$ Não se trata nem de uma forma de voluntarismo cego, nem de uma confiança ingênua no futuro, já que esse humanismo se inscreve num século das trevas e está sempre acompanhado do que Gramsci chamava de "pessimismo da razão", embora comporte também um toque a um só tempo aufklärerisch e tropical, que colore o conjunto de sua obra. Esse otimismo antropológico não o conduz, ${ }^{4}$ Ver a primeira parte de Löwy (1970b). E também Löwy (1999, p. 33-47). 
por certo, à redescoberta da ideia de progresso, oráculo enganoso, hoje silencioso, mas sim à reformulação - em perspectiva utópica - de uma ideia de catástrofe vista como característica marcante do século XX. A "jaula de aço" não existe sem alternativa, e o mundo reificado sem fissuras, o fascismo e o stalinismo não aniquilaram o sujeito histórico da transformação do mundo, pois o olhar do Anjo está horrorizado, mas não resignado. A "porta estreita pela qual o Messias pode entrar", da qual fala Benjamin na conclusão de suas teses "Sobre o conceito de história” (Benjamin, 2000b, p. 443), parecia ter sido reaberta por uma nova geração de revolucionários latino-americanos, pelos operários de São Paulo que criaram o Partido dos Trabalhadores em 1980. Em suma, o "princípio-desespero" de Günther Anders e o "princípio-esperança" de Ernst Bloch não são incompatíveis; antes, eles são os rostos do Janus de duas cabeças que foi o século XX. A revolução não pode mais ser concebida como "locomotiva da história", em uma época em que os trilhos e as locomotivas nos fazem pensar na rampa de Auschwitz, nos comboios em direção aos campos de morte nazistas; ela aparece, ao contrário, como "freio de emergência" diante da catástrofe, mas continua no nosso horizonte de visibilidade, e por alguns $\stackrel{\infty}{\rightarrow}$ momentos ela até mesmo o preenche. ${ }^{5} \mathrm{~A}$ revo. lução se cercou de um halo melancólico, em função das derrotas acumuladas num século de lágrimas e de sangue, mas a sua chama não se apagou. Há alguns anos, Löwy dedicou às

Ver os materiais preparatórios às teses "Sobre o conceito de história” (Benjamin, 1991, p. 1232). Ver também Löwy (2001b). qual ele era pensado essencialmente como uma ciência positiva. Mais tarde, ele estudou a cultura judeu-alemã, não para erigir um monumento em lembrança a uma região desaparecida, e sim para resgatar uma tradição oculta, aquela do messianismo utópico, uma tradição que não se trata de comemorar, mas de reativar, de atualizar no sentido da "rememoração" de Benjamin. Em vários textos, Michael Löwy evoca os murais de Diego Rivera, consagrados à conquista do Novo Mundo, o pensamento indigenista de Mariátegui, ou ainda a teologia da libertação de Gustavo Gutiérrez como ilustrações de uma concepção da história espantosamente próxima à de Walter Benjamin. Em todos esses casos, sublinha ele, o passado é visto do ponto de vista dos vencidos, isto é, da cumplicidade subterrânea e implícita, mas atuante, entre a resistência contra a dominação espanhola e portuguesa e as lutas emancipatórias do presente (Löwy, 2001, p. 65-67). A América Latina é o elo que articula a visão trágica de mundo (Lukács, Goldmann) e o messianismo judaico (Benjamin) em uma nova teoria, a do romantismo revolucionário: uma crítica ao capitalismo que se alimenta da nostalgia em relação ao mundo pré-moderno, mas que, em vez de postular um retorno conservador ao passado, se projeta na direção de um futuro utópico.

A descoberta e a interpretação do romantismo constituem, sem dúvida, a sua principal contribuição à sociologia da cultura e ao pensamento crítico contemporâneo (Löwy; Sayre, 1992). Trata-se de uma teoria que lança um novo olhar sobre dois séculos de história. Antes de tudo, ela parte da crítica às definições restritivas do romantismo, entendido como mera corrente literária ou estética do século XIX, como reação conservadora à revolução francesa, como atitude psicológica subjetiva, ou ainda como corrente filosófica reacionária que prenuncia o fascismo. Essas definições são obviamente válidas, mas permanecem unilaterais na medida em que são incapazes de apreender o fenômeno em toda sua comple- 
xidade. Inspirando-se em Lucien Goldmann, Michael Löwy e Robert Sayre, elas apresentam o romantismo como uma "visão de mundo" fundada na rejeição da civilização industrial burguesa. Seus alvos são os traços centrais da sociedade capitalista moderna: o espírito de cálculo, a mecanização e o "desencanto" do mundo, a racionalidade instrumental, a dominação totalitária dos sistemas anônimos, a reificação das relações sociais, a dissolução de todos os laços comunitários. Nostálgico em relação a um passado em que os seres humanos viviam em harmonia entre si e com a natureza, o romantismo é atraído, de modo profundo, pela religião, pelos mitos, pelas atmosferas noturnas, pelas tradições e símbolos rodeados de uma aura mágica, e, ao mesmo tempo, exprime uma atitude pessimista e desesperada em relação ao tempo presente. Como crítica da modernidade engendrada pelo próprio mundo moderno, o romantismo coexiste com o Espírito das Luzes como uma espécie de "autocrítica da modernidade” (Löwy; Sayre, 1992, p. 35). É assim que Michael Löwy interpretou não apenas Marx e Rosa Luxemburgo, Benjamin e Kafka, Bloch e Marcuse, mas também os surrealistas e Guy Débord, Pierre Naville e Henri Lefebvre, Christa Wolf e Ignazio Silone, E. P. Thompson e Fredric Jameson, José Carlos Mariátegui e Eduardo Galeano, William Morris e Maio de 68. A lista é bem maior e revela o que eu chamaria de tentação bourdiviana (bourdivine $^{6}$ ) de Michael Löwy.

Ao longo dos anos, essa sensibilidade romântica colore cada vez mais sua interpretação de Marx, o que significa, a um só tempo, uma crítica interna e um enriquecimento original. Não seria difícil qualificar o marxismo de Michael Löwy com diversos adjetivos tomados de empréstimo dos seus escritos - humanista,

${ }^{6}$ Neologismo utilizado de modo geralmente pejorativo para se referir às ambições totalizantes da obra do sociólogo francês Pierre Bourdieu. Trata-se de um jogo de palavras entre o nome Bourdieu e o adjetivo divino (divin). A alcunha tornou-se moeda corrente com as reações suscitadas pelo engajamento de Bourdieu em defesa do movimento social que, em novembro de 1995, derrotou a reforma da seguridade social proposta pelo primeiro-ministro Alain Juppé. (Nota do tradutor). historicista, dialético, antipositivista, revolucionário, internacionalista; na realidade, porém, ele é irredutível às numerosas escolas que transitaram pela cena intelectual no decorrer do século XX. Löwy foi inspirado pela revolução cubana e por Rosa Luxemburgo, por Lukács e pela teoria da revolução permanente, mas jamais se reduziu a uma variante do guevarismo, do luxemburguismo, do webero-marxismo ou do trotskismo. Em particular, Löwy jamais acalentou a pretensão de revelar o "verdadeiro" Marx, transformando sua própria leitura em prisma normativo. Ele reconhece a existência de vários Marx. De um lado, um Marx teleológico, positivista, que via o socialismo como resultado do progresso e do desenvolvimento inelutável das forças produtivas. De outro, um Marx dialético e antipositivista, adversário do eurocentrismo e do colonialismo, crítico não somente da exploração capitalista senão da civilização burguesa no seu conjunto, partidário da autoemancipação dos oprimidos mais do que do progresso técnico.

Desde a descoberta do surrealismo, em sua adolescência no Brasil, o marxismo de Michael Löwy contém um forte componente antiautoritário, libertário. Em nome da pluralidade dos marxismos, Löwy reconhece a existência de um marxismo autoritário, mas considera que a principal contribuição de Marx ao pensamento político reside na elaboração da "perspectiva de uma revolução antiautoritária” (Löwy, 1993, p. 17). O marxismo de Löwy é libertário, não anarquista, já que ele jamais preconizou a "abolição" do poder (ainda recentemente, criticou a posição dos que defendem "mudar o mundo sem tomar o poder” Löwy e Holloway (2003, p.13-25), Löwy (2003). E Löwy foi impactado o bastante pelas experiências revolucionárias (e contrarrevolucionárias) da América Latina para trocar a concepção do poder de Marx por aquela - rizomática e inapreensível - de um Foucault. Mas seus escritos políticos nunca apresentam o poder como um fim em si. Diria mesmo que esse tipo de ambição lhe é fortemente estranha: eu 
jamais o vi fazer o menor esforço para conquistar a menor posição diretiva no âmbito de uma instituição científica ou de uma organização política. A posição de Löwy com relação ao intelectual no poder, figura disseminada por todo o planeta, se caracteriza pela incompatibilidade radical, senão pela "separação insuperável” (unversöhnliche Zwiespalt), conforme o termo de Weber a que ele recorre a fim de definir a antítese da afinidade eletiva (Löwy, 1998, p. 35).

A seus olhos, o marxismo é, antes de tudo, uma crítica da dominação e uma teoria da autoemancipação, por ele progressivamente elaboradas como pars construens de uma crítica romântica do mundo desencantado, desumanizado, reificado e cada vez mais ameaçado - tanto no plano social quanto no plano ecológico - pela racionalidade instrumental e cega do capitalismo moderno. Uma vez que a religião pode ser a fonte espiritual da recusa de um mundo remodelado pelo espírito de cálculo, o marxismo - como projeto de transformação social - deve se abrir a diferentes sensibilidades, seculares e religiosas. Em um ensaio sobre o surrealismo, Michael Löwy encontra, em Benjamin e Breton, traços de um marxismo gótico moldado pela fascinação em relação ao encantamento e ao maravilhoso, "um mate-

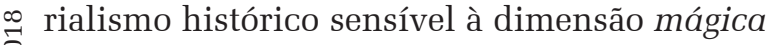
N das culturas do passado" (Löwy, 2000, p. 42).

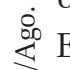
Evidentemente, numa tal leitura de Marx, a imagem dialética da rememoração de uma sociedade sem classes, incorporada na memória coletiva, prevalece em muito sobre a utopia fria de um modelo de sociedade perfeita.

Michael Löwy pertence, de pleno direito, à tradição descrita por Isaac Deutscher dos "judeus não judeus", uma tradição herética criada por judeus que afirmaram sua judeidade transcendendo e transgredindo as fronteiras do judaísmo. Dentre os principais representantes, Deutscher menciona "grandes revolucionários do pensamento moderno", como Spinoza, Heine, Marx, Rosa Luxemburgo, Trotsky e Freud. Segundo Deutscher, um de seus aspectos co- muns vincula-se ao fato de que, "judeus, eles viviam no cruzamento de civilizações, de religiões e de culturas nacionais diversas" (Deutscher, 1969, p. 37). Essa tradição cosmopolita e universalista é, em última instância, incompatível com o sionismo, que redefine a judeidade em termos nacionais. Löwy tentou resgatar, no sionismo, uma corrente "libertária", cujos elementos ele encontrou em alguns escritos de Bernard Lazare, Scholem e Buber. Mostrou a complexidade do fenômeno, resignando-se a reconhecer que, em Israel, o sionismo político havia suplantado o sionismo cultural.

Historicamente, os "judeus não judeus" foram frequentemente intelectuais "párias", exilados, desclassificados, marginais e Aussenseiter. Diretor emérito de pesquisas e detentor de uma medalha de prata no Centre Nationale des Recherches Scientifiques (CNRS), Löwy não é, por certo, um pária social. Suponho, porém, que ele deva ter sentido alguma empatia existencial por esses párias judeus quando retraçou seus percursos em um de seus mais belos livros, Redenção e Utopia (Löwy, 1988, p. 38-61). Segundo Hannah Arendt, os párias eram indivíduos sem Estado que, idealmente cidadãos do mundo, viviam na condição de verdadeiro "acosmismo", ou falta de mundo (Weltlosigkeit) (Arendt, 2007, p. 275-297). Instalado na Europa posterior à Segunda Guerra Mundial, Löwy não foi afetado por essa "falta de mundo", mas sim por uma "sede de mundo", que ele logrou amplamente satisfazer, circulando pelo planeta como intelectual nômade, professor convidado por dezenas de universidades e militantes altermundialistas. Durante os anos 1930, os exilados judeus deixaram a Europa e encontraram refúgio nas Américas; Löwy fez o caminho inverso, deixando o Brasil para se instalar na Europa. Há, aqui, o signo de uma fidelidade, da inscrição em uma história e em uma continuidade.

No artigo sobre o surrealismo, Löwy relembra a crítica de Benjamin a esse movimento estético e político. Breton e seus amigos haviam redescoberto uma "ideia radical de li- 
berdade" que a Europa parecia ter perdido desde Bakunin, mas eles se revelaram incapazes de dotar essa revolta de um caráter "metódico e disciplinar" (Benjamin, 2000a, p. 129-130; Löwy, 2000, p. 45-46). Ora, Michael Löwy, marxista e surrealista desde a adolescência, sempre foi extremamente organizado e metódico. Roberto Schwarz, seu amigo desde essa época em São Paulo, destaca, a esse respeito, que a observação de Benjamin segundo a qual os surrealistas, com seu culto da embriaguez, desconheciam o valor místico do trabalho, não se aplica a Löwy. Apresentando-o como resultado de uma "combinação de surrealismo e de sentimento de dever (obrigação)", Schwarz esboça um retrato simpático do jovem Michael, um retrato que apreende perfeitamente alguns traços de sua personalidade. Michael, escreve ele,

... era muito cumpridor de seus deveres e muitíssimo bem organizado. Graças a isso, ele tinha tempo para tudo. Era excelente aluno, lia e fichava o que os professores pediam, entregava os trabalhos na data prevista, era militante político assíduo, pontual nas passeatas, ia aos concertos, via os filmes, fazia a corte às moças, de meio-dia a uma ouvia a Hora dos mestres, um programa de música clássica da Rádio Gazeta, gostava de jogar os jogos surrealistas, que ensinava a amigas e amigos, e, até onde sei, era um filho muito dedicado, o que se poderia chamar um bom menino (Schwarz, 2007, p. 157).

Conheci Michael bem mais tarde, mas tive, desde o princípio, uma impressão semelhante. Sua grande biblioteca está sempre perfeitamente organizada e eu nunca encontrei seu escritório tomado por folhas, livros, notas, conforme a alegre confusão que muitas vezes acompanha os espíritos criativos. Seu trabalho de escrita é bastante metódico e ordenado. Sempre me intrigou a multiplicidade de seus engajamentos: a lista de associações e de redações de revistas das quais é membro é amplíssima. O cumprimento metódico dos deveres (intelectuais e militantes) modela sua conduta de vida. Uma vez que foi ele quem me introduziu a Max Weber, devo confessar que Michael Löwy, muitas vezes, me pareceu uma boa ilustração da definição weberiana da ética protestante, com sua organização racional da vida e mesmo sua "ascese intramundana". Evidentemente, não se trata, no seu caso, sob nenhuma hipótese, de qualquer relação de afinidade eletiva com o espírito do capitalismo - poder-se-ia falar, na verdade, de hostilidade irredutível. Tampouco da tendência a rejeitar os prazeres da vida, que são, antes, planificados e apreciados com moderação. Desse ponto de vista, sob o risco do clichê, diria que ele sempre me pareceu bem pouco latino-americano. Raramente suas noitadas, mesmo as mais conviviais, vão além das 23h30min, momento no qual, para muitos latino-americanos, a verdadeira festa começa. É quase certo, aliás, que jamais assistirei com Michael uma final da Copa do Mundo de futebol entre Brasil e França, ou entre Brasil e Itália. Cheguei à conclusão de que essa dimensão "protestante" é um traço típico dos yekes, os judeus alemães, pois a encontrei em outros amigos, ainda que sob uma forma menos "ideal-típica". Se a revolução é, como a concebem os surrealistas, uma irrupção repentina de liberdade, que quebra as correntes e subverte as normas, sua preparação é um trabalho metódico.

Em 1997, Michael me enviou a reedição de seu primeiro livro, A teoria da revolução no jovem Marx. Na dedicatória, ele o apresenta como "uma obra de juventude, sobrevivente do Parque Jurássico”. No prefácio, porém, não há quase crítica alguma em relação ao livro que ele próprio definira como uma espécie de vestígio arqueológico: o texto se ocupa mais dos enriquecimentos realizados desde então do que daquilo que teria sido superado. Essa observação é anedótica, mas também reveladora da continuidade substancial de uma obra, elaborada a partir de um núcleo - o marxismo como teoria da revolução - que conheceu, ao longo dos anos, redefinições e reformulações, e não questionamentos profundos. Sua obra se enriqueceu através de um processo de estratificação no qual cada camada se superpôs ou se enxertou sobre as outras sem as descartar 
ou as enterrar. Ela se revelou sempre aberta e curiosa, o contrário de um pensamento congelado e replicado em si mesmo, mas nunca foi perpassada por grandes tensões internas, nem atravessada por contradições visíveis no longo prazo. Michael nunca foi dogmático, mesmo em uma época em que tal postura era bastante frequente, mas nunca foi, por outro lado, tomado por dilemas dolorosos. Essa continuidade sempre me fascinou e também, confesso, me espantou um pouco, como se, para ele, a dialética fosse uma esponja capaz de absorver tudo, de superar todas as contradições, tal como um dos seus mots d'esprit preferidos, tomado do humor judaico, no qual um rabino profere opiniões contraditórias a fim de satisfazer todo mundo.

No início dos anos 1960, quando escrevia sua tese, transformada em seu primeiro livro, Michael jamais teria definido o marxismo como um "messianismo ativo que trabalha as dores do presente” (Löwy, 1997, p. 18), mas já acreditava na fórmula que descobriria algumas décadas mais tarde, no Livro das Passagens de Benjamin: "O capitalismo não morrerá de morte natural". No limite, penso que a exigência de mudar o mundo, e não apenas de interpretá-lo, foi sempre o verdadeiro horizonte de sua vida e de seu pensamento. Sua obra contém algumas œ "iluminações profanas" que nos são preciosas. ก E essa continuidade abriga, creio, um dos segre$\stackrel{\Delta}{\longrightarrow}$ dos de sua surpreendente juventude.

Recebido para publicação em 17 de janeiro de 2018 Aceito em 21 de maio de 2018

\section{REFERÊNCIAS}

ANTUNES, R. "Anotações sobre uma bela singularidade". In: JINKINGS, I; PESCHANSKI, J. A. (Orgs.). As utopias de Michael Löwy. Reflexões sobre um marxista insubordinado. São Paulo: Boitempo Editorial, 2007.

A ARENDT, H. "The Jew as Pariah: a hidden tradition”. In: The Jewish Writings. Nova York : Schocken Books, 2007.

そ BENJAMIN, W. Gesammelte Schriften. Frankfurt: Suhrkamp, 1991.
BENJAMIN, W. "Le surréalisme”. In: CEuvres II Paris: Gallimard, 2000a.

BENJAMIN, W. "Sur le concept d'histoire". In: CEuvres III. Paris: Gallimard, 2000b.

DEUTSCHER, I. Essais sur le problème juif. Paris: Payot, 1969.

GOLDMANN, L. "Pour um approche marxiste aux études sur le marxisme”. In:___ Annales. 1963. n.1.

JUDT, T. Une histoire de l'Europe depuis 1945. Paris: Armand Colin, 2007.

LÖWY, M. La pensée de Che Guevara. Un humanisme révolutionnaire. Paris: Maspero, 1970a.

La théorie de la révolution chez le jeune Marx. Paris: Editions Sociales, 1970b.

LÖWY, M. "L'humanisme historiciste de Marx ou relire Le Capital”. In:_ . Contre Althusser. Paris : UGE, 1974

1980.

Le Marxisme en Amérique Latine. Paris: Maspero,

Paysages de la vérité. Introduction à une sociologie

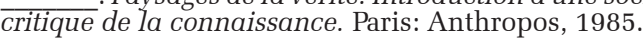

Rédemption et utopie. Le judaïsme libertaire en Europe centrale. Paris: PUF, 1988.

LÖWY, M. "Marxism and Utopian Vision". In:

On Changing the World. Essays in political philosophy, from Karl Marx to Walter Benjamin. Atlantich Highlands: Humanities Press, 1993.

La Guerre des dieux. Religion et politique en Amérique Latine. Paris: Éditions du Félin, 1998.

"L’humanisme révolutionnaire d'Ernest Mandel". In: ACHCAR, G. (Org.). Le marxisme d'Ernest Mandel. Paris: PUF, 1999. Syllepse, 2000.

L'Étoile du matin. Surréalisme et marxisme. Paris:

"La dialettica dela civilità: figure dela barbárie modera nel XX secolo”. In: GLORES, M. Storia, veritá, giustizia. I criminidel XX secolo. Milão : Bruno Mondadori, 2001a.

Walter Benjamin, avertissement d'incendie. Une lecture des thèses "Sur le concept d'histoire". Paris: PUF, $2001 \mathrm{~b}$.

LÖWY, M. «The only true emancipation». New Politics, [s.1], v. 9, n. 35, 2003.

LÖWY, M.; BESANCENOT, O. Che Guevara. Une braise qui brûle encore. Paris: Mille et une nuits, 2007.

LÖWY, M.; HOLLOWAY, J. «Intercambio entre Michael Löwy y John Holloway». Bajo el Volcán, [s.l], v. 3, n. 6, 2003

LÖWY, M.; NAÏR, S. Lucien Goldmann ou la dialectique de la totalité. Paris: Seghers, 1973.

LÖWY, M.; SAYRE, R. Révolte et mélancolie. Le romantisme à contra-courant de la modernité. Paris: Payot, 1992.

SCHWARZ, R. "Aos olhos de um velho amigo". In: JINKINGS, I.; PESCHANSKI, J. A. (Orgs.). As utopias de Michael Löwy. Reflexões sobre um marxista insubordinado. São Paulo: Boitempo Editorial, 2007. 
THE LIBERTARIAN MARXISM OF MICHAEL LÖWY

\author{
Enzo Traverso
} In this essay, originally delivered as a conference,
Enzo Traverso analyzes some of the strengths of Michael Löwy's intellectual trajectory, from his early work son Marx, Lukacs, and Goldmann to his more recent reflection son Benjamin or on Romanticism. Applying to the author's analysis the same method that he used to understand the authors he investigated, Traverso defends the hypothesis that, although born in Brazil, Löwy can be seen as a "French intellectual who combines and surpasses two traditions that marked deeply history, culture and politics of the twentieth century: that of Central European Judaism before Schoah and that of the Latin American left after the Cuban revolution."

KeYwords: Intellectuals. Judaism. Central Europe. Latin America. Libertarian Marxism.
LE MARXISME LIBERTAIRE DE MICHAEL LÖWY

\author{
Enzo Traverso
}

Dans cet essai, à l'origine livré comme une conférence, Enzo Traverso analyse certains des fils conducteurs du parcours intellectuel de Michael Löwy, depuis ses premiers travaux sur Marx, Lukacs et Goldmann à ses réflexions plus récentes sur Benjamin ou sur le romantisme. Appliquant à l'analyse de l'auteur la même méthode qu'il avait utilisée pour comprendre les auteurs sur lesquels il a travaillé, Traverso soutient l'hypothèse selon laquelle, bien que né au Brésil, Löwy peut être considéré comme un "intellectuel français unissant et dépassant deux traditions qui ont profondément marqué l'histoire, la culture et la politique du XXe siècle: celle du judaïsme d'Europe centrale d'avant la Schoah et celle de la gauche latino-américaine d'après la révolution cubaine”.

Mots-CLÉs: Intellectuels. Judaïsme. Europe centrale. Amérique latine. Marxisme libertaire.

Enzo Traverso - Doutor em Sociologia. Professor do College of Arts \& Sciences da Universidade de Cornell, nos EUA. Autor de vários livros, dentre os quais Les marxistes et la question juive; Histoire d'un débat 1843-1943 (1990); Siegfried Kracauer. Itinéraire d'un intellectuel nomade (1994); La pensée dispersée. Figures de l'exil judéo-allemand (2004); La fin de la modernité juive. Histoire d'un tournant conservateur (2013); Mélancolie de gauche: La force d'une tradition cachée (2016), publicado em diversas línguas. 
